\title{
Stress partitioning in streams by large woody debris
}

\author{
Michael Manga \\ Department of Geological Sciences, University of Oregon, Eugene \\ James W. Kirchner \\ Department of Geology and Geophysics, University of California
}

\begin{abstract}
Using simple theoretical models and field measurements from a springdominated stream, we quantify how large woody debris affect channel hydraulics and morphology at both the local and reach-averaged scales. Because spring-dominated streams have nearly constant discharge, they provide a unique natural opportunity to study flow and transport processes near the channel-forming flow. We first show that the drag on a floating log is identical to the theoretical value for widely separated cylinders at similar Reynolds numbers. We then use simple theoretical models to estimate the partitioning of flow shear stress between woody debris and streambeds. The inferred stress partitioning is consistent with an estimate based on a comparison of local and reachaveraged measurements of the water surface slope. Our measurements show that even though large woody debris cover less than $2 \%$ of the streambed, they provide roughly half of the total flow resistance. As large woody debris are added to a stream, the total shear stress increases (because the water depth increases), but the shear stress borne by the bed decreases, as a growing fraction of the total shear stress is borne by the debris. Our analysis shows that simple theoretical models of stress partitioning may provide a convenient mathematical framework for assessing how changes in debris loading affect streams.
\end{abstract}

\section{Introduction}

Large woody debris lying in streams, hereafter abbreviated LWD, can greatly influence channel properties and morphology. For example, by locally redirecting the flow of water, LWD create backwaters, local scour, and thus various types of pools [e.g., Robison and Beschta, 1990]. Owing to the increased flow resistance provided by the addition of debris to a stream there can be a net increase in sediment storage [Smith et al., 1993], changes in bed texture [Buffington and Montgomery, 1999], and changes in sediment transport [Assani and Petit, 1995]. In addition, by changing local and reach-averaged hydraulic conditions, LWD may affect the stability of channel banks [e.g., Bilby, 1984; Nakamura and Swanson, 1993; Trimble, 1997; Montgomery, 1997]. Because bed texture, pool geometry, the variability of local stream flow, and the woody debris themselves all affect fish habitat [Beechie and Sibley, 1997], quantifying the various processes associated with LWD in streams is important for guiding stream protection and restoration efforts [e.g., Gippel et al., 1996; Piégay and Gurnell, 1997].

Changes in stream flow and hydraulic properties at both the local scale and reach-averaged scale are due to the additional roughness, or flow resistance, provided by the LWD. In turn, the contribution to flow resistance by LWD depends on both the hydraulic conditions in the river and geometrical characteristics of the LWD, e.g., the density and spacing of debris and the size of debris relative to the flow depth [e.g., Ranga Raju et al., 1983; Shields and Gippel, 1995].

Our goal in the present study is to use field measurements to determine how LWD affect the overall partitioning of flow resistance in a channel. The total channel shear stress

Copyright 2000 by the American Geophysical Union.

Paper number 2000WR900153.

0043-1397/00/2000WR900153\$09.00

$$
\tau_{0}=\rho g R s
$$

is the weight of water in the downstream direction per unit area of the bed. Here, $\rho$ is the water density, $g$ is gravity, $R$ is the hydraulic radius, and $s$ is the slope of the energy grade line. Assuming steady, uniform flow (convective accelerations can be neglected), $\tau_{0}$ is partitioned between various components, each of which characterizes a particular roughness element [e.g., Einstein and Banks, 1950]

$$
\tau_{0}=\tau_{G S}+\tau_{B F}+\tau_{\text {LWD }}+\tau_{\text {others }} .
$$

The grain stress $\tau_{G S}$ is the effective shear stress at the bed that is available for sediment transport. The $\tau_{B F}$ is the stress component due to bed forms, and $\tau_{\mathrm{LWD}}$ is the stress due to large woody debris.

In this paper we first use field measurements to calculate the relative contribution of LWD to the reach-averaged total stress; that is, we determine $\tau_{\mathrm{LWD}} / \tau_{0}$. We then compare our field-based results to theoretical models and briefly consider some of the geomorphological implications of the reachaveraged increase in roughness due to LWD. The effect of debris on flow resistance has been considered in numerous studies (see reviews by Lisle [1995] Gippel [1995], and Dudley et al. [1998]); the present study differs from previous work in the nature of the measurements that are considered (fielddetermined drag measurements, water surface slope) and the hydrological setting.

\section{Hydrological Setting}

We will focus on measurements made in the Cultus River, a gravel bed stream in the central Oregon Cascades. This stream is fed entirely from springs at the base of Bench Mark Butte. The region surrounding the stream channel is a relatively flat outwash plain covered by lodgepole pine. The streambed of 

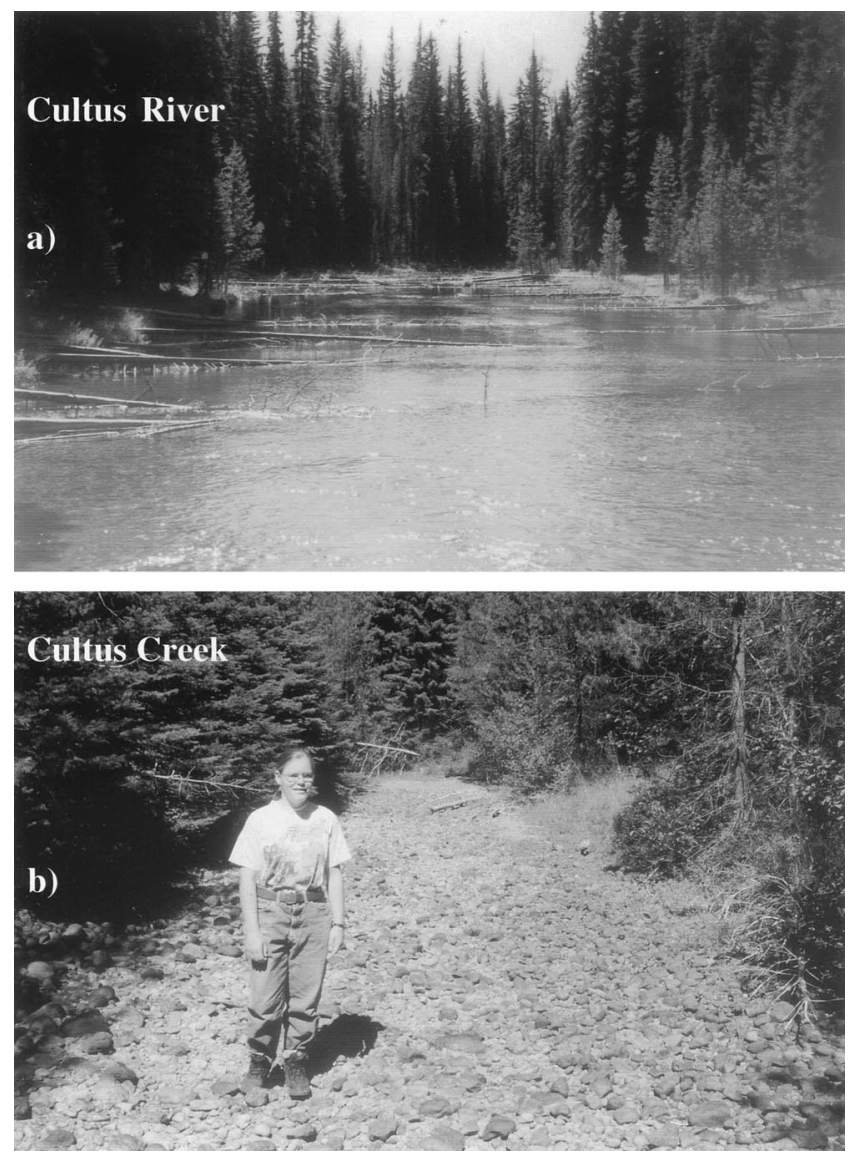

Figure 1. (a) Spring-fed Cultus River, Oregon, and (b) runoff-dominated Cultus Creek, Oregon. Photographs are taken on the same day in September and at the same elevation. Mean and peak discharges over the period 1939-1989 are 1.8 and 4.3 $\mathrm{m}^{3} / \mathrm{s}$ for the Cultus River and 0.6 and $6.8 \mathrm{~m}^{3} / \mathrm{s}$ for Cultus Creek. Channel width in Figure 1a is $\sim 25 \mathrm{~m}$.

the Cultus River consists primarily of glacial outwash associated with the Suttle Lake advance [Scott, 1977]. Bedrock is not exposed in the streambed or along the banks. Near the source of the stream there are a small number of rock fragments derived from rockfalls from Bench Mark Butte.

Spring-fed rivers, such as the Cultus River, typically have rectangular channel cross sections and unusually large width to depth ratios [Whiting and Stamm, 1995]. The bank-full width to depth ratio of the Cultus River averages about 50, and its cross sections are indeed approximately rectangular. The other distinctive feature of spring-fed streams is that discharge variations are small. For example, between 1939 and 1989 the mean discharge $\bar{Q}$ in the Cultus River was $1.79 \mathrm{~m}^{3} / \mathrm{s}, Q_{95}$ was 2.80 $\mathrm{m}^{3} / \mathrm{s}$, and $Q_{5}$ was $1.05 \mathrm{~m}^{3} / \mathrm{s}$. The limited range of discharge reflects the long mean residence time (years to decades) of the groundwater that emerges at the springs [Manga, 1999]. In Figure 1 we show photographs of spring-fed Cultus River and nearby runoff-dominated Cultus Creek. Both photographs were taken on the same day in September 1997. The photographs were taken at the same elevation and $\sim 500 \mathrm{~m}$ from each other. Notice that in the Cultus River the trees lying in the river are well separated and are oriented approximately perpendicular to the bank. This is in contrast to the more common situation, especially in low-order streams, in which trees accumulate in debris piles as a result of the transport and "sedimentation" of debris [Piégay et al., 1999]. Thus one consequence of the absence of large floods in these spring-fed channels is that trees that fall into the stream are not easily carried downstream. In the Cultus River, trees fall into the water because of wind throw or bank erosion undercutting the trees. As shown later in Figure 3 the trees are found at all water depths, from above the surface to the stream bottom. In order to highlight the small discharge variations in spring-fed streams, in Figure 2 we show the flood frequency curves for the two streams shown in Figure 1 and a 60 -year hydrograph for the Cultus River.

The shape of the channel cross section, the stability of the channel shape and position, and the nearly constant flow all make spring-fed streams ideal for studying the effects of LWD on stress partitioning. The near-constant discharge ensures that the flow conditions under which we make our measurements will be typical of those that prevail in the stream. In fact, during the period over which we made our measurements (September and October 1997), flow was typically around $Q_{90}$ (see Figure 2), and near bank-full because of the high precipitation between October 1996 and April 1997. Spring-fed streams thus offer a distinct advantage over other fluvial systems, in which the channel-forming discharge is typically orders of magnitude higher than the discharge at which field measurements can be easily made. In some ways, spring-fed rivers such as the Cultus River can be thought of as large natural flumes that have been operating continuously for long periods of time.

Because the water emerging from the springs contains vir-
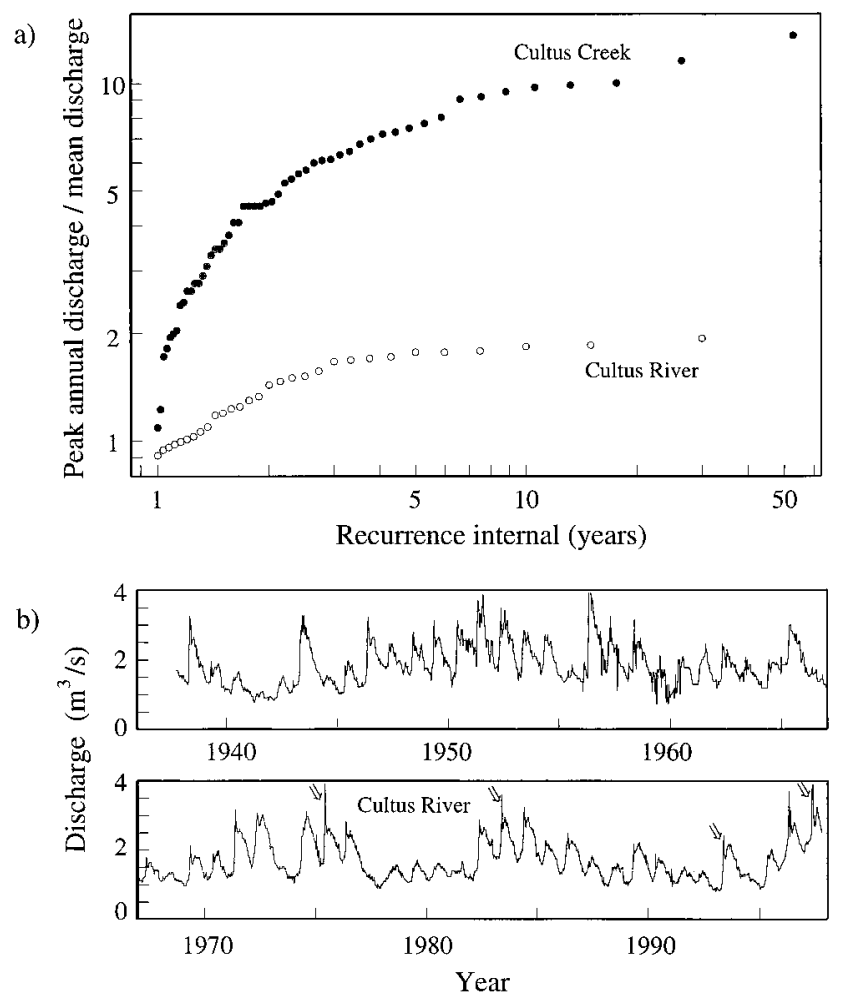

Figure 2. (a) A comparison of flood frequency relationships for spring-fed Cultus River and runoff-dominated Cultus Creek. (b) Hydrograph for the Cultus River. The arrows indicate peaks that represent flow from a small runoff-dominated stream that enters the Cultus River upstream of the gauging station [Manga, 1997] and downstream of the studied reach. 
tually no sediment load and the region surrounding the river is flat, the supply of fresh bed material is limited to that which is eroded from the channel banks. The rate of channel migration must be small, however, because soil cores from both banks reveal a layer of ash from the $\sim 7000$ years B.P. eruption of Mount Mazama. The current bed is probably produced by winnowing of the glacial outwash. Because the rate of sediment supply is extremely low, we would expect the sediment that remains on the bed to be below the threshold of initial motion under almost all flow conditions. Because the flow conditions are not highly variable, the threshold of initial motion should lie only slightly above the bed stresses that we measure.

\section{Measurement Techniques}

In order to determine $\tau_{\text {LWD }}$ we surveyed a $90-\mathrm{m}$ reach of the river. The elevation of the stream bottom, the water surface, and LWD locations were determined using a total station. The orientations of LWD were measured with a Brunton compass. We surveyed the approximate geometric centerline of the channel because the thalweg is poorly defined in this stream and other spring-dominated streams [Whiting and Stamm, 1995]. Water surface elevation was measured relative to the stream bottom.

Water velocities were measured using a Price pygmy current meter mounted on a hand-held wading rod and are based on a measurement period of 40-120 s. The local depth-averaged velocity $U$ was determined by measuring the velocity at a depth of 0.6 of the flow depth where the water depth is less than $0.35 \mathrm{~m}$ and by averaging the velocities at 0.2 and 0.8 of the water depth for depths greater than $0.35 \mathrm{~m}$. The size of bed materials was determined by collecting between $\sim 1$ and $3 \mathrm{~kg}$ of the surface layer of the bed. Bed samples were dried, and particle sizes were determined by sieve analysis. All measurements and sampling were done by the same person in order to eliminate variability due to different biases between different individuals [Wohl et al., 1996]. The extent to which we are able to accurately characterize the size distribution of bed materials is difficult to determine: During the collection of the surface layer, finer components can be carried away; inevitably we also collect some of the bed's subsurface, which typically contains finer particles than the surface layer [e.g., Church et al., 1987].

\section{Results and Discussion}

In order to determine the partitioning of stress we first determine an appropriate value of the drag coefficient for LWD in these streams (section 4.1). Next we use a force balance equation to estimate stress partitioning (section 4.2). We then show that the inferred stresses are consistent with surveyed water surface slope measurements (sections 4.3 and 4.4). Finally, we consider the interaction between LWD and the streambed (section 4.5).

\subsection{Drag on LWD: Direct Measurements}

Consider an object immersed in a uniform flow with velocity $U$. The force $F$ per unit area on this object will be

$$
\frac{F}{A}=\frac{1}{2} \rho C_{D} U^{2},
$$

where $A$ is the object's cross-sectional area perpendicular to the flow and the constant of proportionality $C_{D}$ is the drag coefficient. $C_{D}$ can depend on the Reynolds number, Froude number, object shape, and the object's orientation. In a channel of finite size, $F / A$ may additionally depend on $A$ and the object's position in the channel. Given the importance of quantifying the resistance to flow in channels, there are a large number of studies of $C_{D}$ for objects such as vegetation, bed forms, and large particles. Of relevance for the present study is the drag on approximately horizontal cylinders with diameters of the same order of magnitude as the flow depth. A complete literature review will not be provided here, and the reader is referred to a summary of relevant experimental results provided by Shields and Gippel [1995].

Before applying the results of flume-based drag measurements to our stream we wanted to verify that these are compatible with the actual in-stream drag on LWD. There are three main reasons why flume-based drag coefficients for cylinders might differ from drag coefficients in natural settings. First, the streambed of our gravel bed river is rough, and the typical diameters of LWD $(H \approx 20 \mathrm{~cm})$ are not orders of magnitude different from the scale of bed roughness $\left(d_{90} \approx\right.$ $3-4 \mathrm{~cm}$ ) and the mean water depth (here $\bar{h} \approx 36 \mathrm{~cm}$ ). Second, the velocity in a natural channel varies with depth. Finally, many of the LWD in the channel are partially above the water surface, so that there is a free surface that can interact with the flow and the LWD.

In order to determine the drag on LWD we made field measurements on a floating log with dimensions comparable to the LWD in the stream: The log length was $4.61 \mathrm{~m}$, the diameter was $\approx 12 \mathrm{~cm}$ (diameter varied between 11.5 and $13.5 \mathrm{~cm}$ ), and the mean depth of the log below the water surface was $H=7 \mathrm{~cm}$. To measure the force on the log, we attached springs to the ends of the log. The springs were attached to strings that, in turn, were attached to a fixed object about $10 \mathrm{~m}$ upstream. The springs and string were kept above the water surface. We can then use Hooke's law to relate the orientation of the stretched springs and the magnitude of the spring stretching to the force on the log. These measurements were made in a LWD-free region where the water depth was nearly constant across the entire channel $(\bar{h}=29 \mathrm{~cm})$. Over the cross section where the log was floating, the depth-averaged water velocity $U$ varied between 0.29 and $0.32 \mathrm{~m} / \mathrm{s}$ with a mean of $0.31 \mathrm{~m} / \mathrm{s}$. The Reynolds number $R e=\rho U H / \mu$ is thus $2.6 \times$ $10^{4}$, where $\rho$ and $\mu$ are the density and viscosity of water, respectively. The inferred drag coefficient from (3) is $1.96 \pm$ 0.3 . The largest uncertainties are associated with (1) the crosssectional area of the log below the water surface $(\approx 10 \%)$ and (2) determining Hooke's constant for our springs (estimated to be $\sim 5 \%$ ).

For comparison the drag coefficient on a circular cylinder at a similar Reynolds number is $\sim 1.1$ [Batchelor, 1967]. Our larger value of $C_{D}$ based on field measurements, however, is due to the finite size of the log relative to the water depth. The field-determined $C_{D}$ is really an apparent drag coefficient $C_{D}^{\text {app }}$ that depends on the so-called blockage effect [Ranga Raju et al., 1983; Shields and Gippel, 1995]. The blockage $B$ is defined as the ratio of obstruction area to cross-sectional flow area, which reduces to $B=H / \bar{h}$ for LWD lying across the channel. Shields and Gippel [1995] report on an experimental study of the effect of blockage [Gippel et al., 1992, 1994] which found that

$$
C_{D}^{\mathrm{app}} \approx \frac{C_{D}}{(1-B)^{2}}
$$



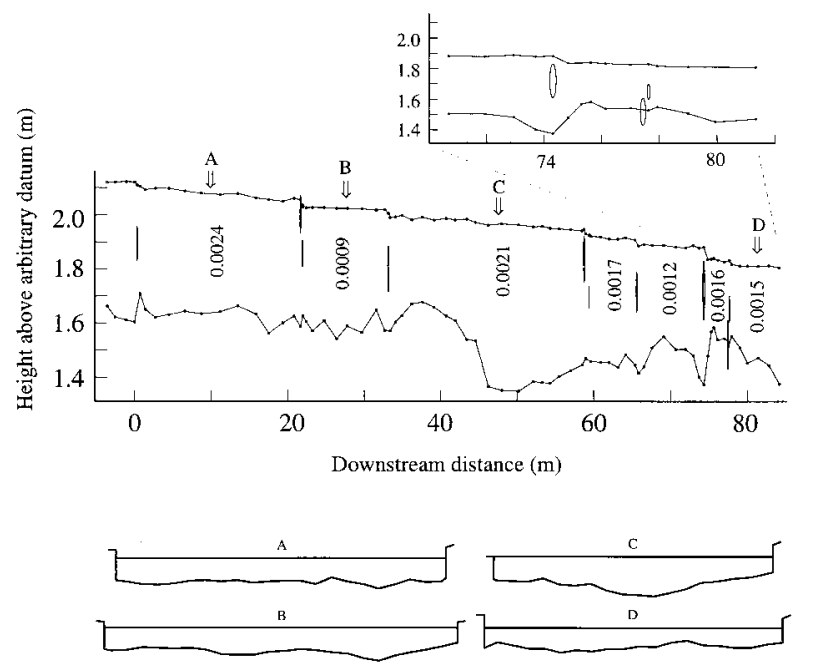

$10 \mathrm{~m}$

Figure 3. Water surface and bed elevation along the middle of the Cultus River. The location and size of LWD are shown; because of vertical exaggeration, LWD (plotted as circles) appear as vertical ellipsoids in the figure. The four channel cross sections shown at the bottom of the figure were made at positions A, B, C, and D indicated in the long profile. Channel cross sections are exaggerated vertically by a factor of 5 .

where $C_{D}$ is the drag coefficient for a cylinder. These measurements are consistent with using a velocity in (3) that represents the mean speed of the water as it is diverted around the $\log$ [Ramamurthy and $\mathrm{Ng}, 1973$ ]: Conservation of mass requires that the mean velocity increases by an amount $U /(1-B)$, where $U$ is the mean velocity upstream of the $\log$.

For the $\log$ considered here, $B=H / \bar{h}=0.24$. Using the field-determined value of $C_{D}^{\text {app }}=1.96 \pm 0.3$, we obtain $C_{D}=$ $1.14 \pm 0.17$, consistent with $C_{D}$ for circular cylinders at similar Reynolds numbers.

\subsection{Drag on LWD: Theoretical Considerations}

A theoretical estimate of the reach-averaged resistance or drag from LWD can be obtained by dividing the drag force acting on LWD by the area of the bed [e.g., Clifford et al., 1992; Nelson et al., 1993; Robert, 1997], i.e.,

$$
\tau_{\mathrm{LWD}}=\rho C_{D}^{\mathrm{app}} \frac{H}{2 L} U^{2},
$$

where $L$ is the distance between LWD.

In Figure 3 we show the surveyed long profile of the study reach along with the water surface, LWD positions and sizes, and four channel cross sections. Over this reach the water depth and channel width are approximately constant, and the reach is straight, so the assumption of uniform flow should be a reasonable approximation.

As we found in section 4.1, $C_{D}^{\text {app }}$ depends on the blockage $B=H / \bar{h} . C_{D}^{\text {app }}$ may also depend on spacing between LWD: As the distance between trees decreases, $C_{D}^{\text {app }}$ will decrease because of the overlap of the wakes created by each piece of debris. The pattern of LWD spacing can also affect $C_{D}^{\text {app }}$, with a staggered distribution of debris providing the greatest resistance for a fixed density of LWD [Li and Shen, 1973]. However, here the mean distance between pieces of debris is $\sim 60$ times their diameters, so that we can, to a good approximation, neglect the hydrodynamic interaction between LWD due to wake interference [Nowell and Church, 1979].

The drag coefficient on a circular cylinder is between $\sim 1.0$ and 1.2 for $10^{3}<R e<10^{5}$. Here $R e \approx 7 \times 10^{4}$. Assuming $C_{D}=1.1$ and using mean values from the surveyed measurements for the variables in (5) $(H / L=0.017, U=0.36 \mathrm{~m} / \mathrm{s}$, $\bar{h}=0.36 \mathrm{~m}$, and $B=0.56)$, we obtain $\tau_{\mathrm{LWD}}=5.8 \mathrm{~Pa}$. In the surveyed reach the mean width of the channel $(24 \mathrm{~m})$ is much greater than the mean depth $\bar{h}$. The hydraulic radius $R$ will thus be very nearly equal to $\bar{h}$. Assuming uniform flow over this reach so that the bed slope equals the slope of the energy grade line, the total stress $\rho g \bar{h} \bar{s}_{b}=12.3 \mathrm{~Pa}$, where $\bar{s}_{b}$ is the average bed slope. Thus while LWD cover less than $2 \%$ of the stream bed, the LWD provide nearly half the flow resistance in the stream.

We can examine, in more detail, the role LWD density plays in stress partitioning. A force balance equation for the case in which only bed and LWD roughnesses need to be considered may be written as [e.g., Nepf, 1999]

$$
\underbrace{\rho C_{B} U^{2}}_{\tau_{G S}}+\underbrace{\rho C_{D}^{\text {app }} \frac{H}{2 L} U^{2}}_{\tau_{\text {LWD }}}=\underbrace{\rho g \bar{h} \bar{s}_{b}}_{\tau_{0}},
$$

where $C_{B}$ is the drag coefficient for the bed. Again, the superscript app on $C_{D}^{\text {app }}$ is used to indicate that this drag coefficient is only its apparent value in the stream. The first and second terms in (6) are equivalent to $\tau_{G S}$ and $\tau_{\mathrm{LWD}}$ in (2), and the right-hand side is $\tau_{0}$ in (1) and (2).

In Figure 4 we show the relationship between $\tau_{0}, \tau_{G S}$ and $\tau_{\text {LWD }}$ as debris are added to this reach. The effective drag coefficient for the streambed $C_{B}$ is chosen to satisfy (6) for the present-day density of LWD, for which we just estimated $\tau_{\text {LWD }}=5.8 \mathrm{~Pa}$ and $\tau_{0}=12.3 \mathrm{~Pa}$. The various stresses are determined by substituting (4) into (5) and solving the resulting nonlinear equation for a fixed discharge, channel width, and slope. As the density of debris increases, the total stress $\tau_{0}$ increases because the water depth increases. Nevertheless, $\tau_{\text {LWD }}$ increases more rapidly, so that there is still a net decrease of stresses on the bed $\left(\tau_{G S}\right)$ as debris are added to the stream.

In (6) and Figure 4 we have ignored the effect of bed forms;

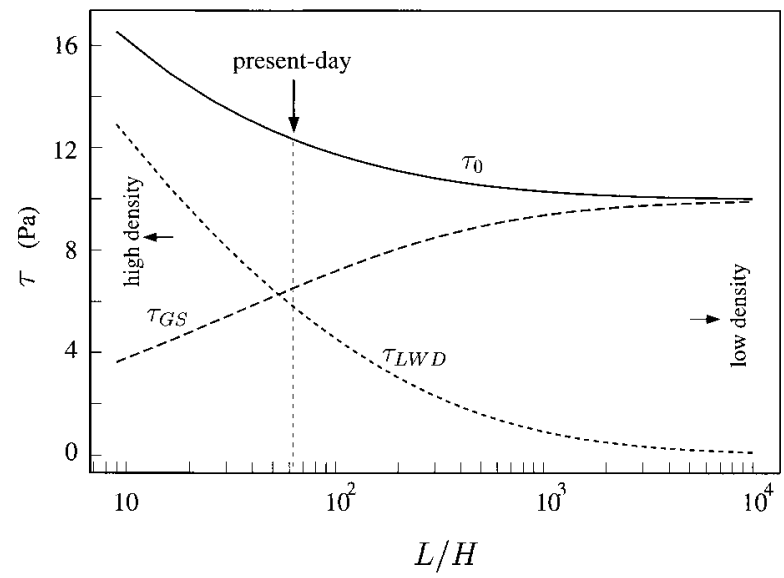

Figure 4. Relationship between debris spacing $L / H$, the total stress $\tau_{0}$, the grain stress $\tau_{G S}$, and the LWD stress $\tau_{\mathrm{LWD}}$ for the Cultus River; $L$ is the mean distance between trees, and $H$ is the mean diameter of trees. 
thus $\tau_{G S}$ and $C_{B}$ for the present-day conditions implicitly characterize the roughness due to the bed and bed forms. Previous studies have shown that bed forms can provide a substantial fraction of the flow resistance in both sand and gravel bed streams [e.g., Prestegaard, 1983; Hey, 1988]. Here, however, the height of bed forms is, in general, smaller than the diameters of the LWD (see Figure 3), and their spatial extent is smaller than that of the LWD (the latter span most of the channel width). Moreover, bed forms are located near the bottom of the channel where velocities are lowest, and recall that drag scales with velocity squared. Last, the few bed forms that do exist resemble bumps or depressions that have a small cross-stream extent compared to the LWD: Thus $C_{D}$ in (3) for three-dimensional flow over such bed forms might be more similar to that for spheres (0.4-0.5) than $C_{D}$ for two-dimensional cylinders $(1.0-$ 1.2). Overall, we thus expect irregularities in the Cultus River's stream bottom to provide a small contribution to flow resistance compared to that provided by LWD. It is important to note that in most streams, as discussed in the introduction, LWD can influence channel morphology and thus the contribution of bed form drag to channel roughness. In the more general case, (6) would have a term for bed form roughness in which the characteristics of the bed forms might also depend on the LWD size and spacing (i.e., $H / L)$.

\subsection{Drag Inferred From Water Surface Slope Measurements}

In Figure 3 the reach-averaged bed slope $\bar{s}_{b}$ is 0.00346 whereas the water surface slope $s_{w}$ between LWD is in the range 0.0009-0.0021. At the subreach scale (in between the LWD) the flow is no longer uniform because water and bed slopes are not equal. Following the approach of Robert [1997], from energy arguments we can estimate the energy gradient $s$ in (1) and (2) as

$$
s=s_{w}-F r^{2}\left(s_{w}-s_{b}\right),
$$

where $F r=U /(g h)^{1 / 2}$ is the Froude number. $F r$ for the Cultus River is $\approx 0.19$ so that equating $s$ and $s_{w}$ amounts to an error of $\sim 3 \%$.

If we attribute the reduction in the slope of the water surface to the additional resistance provided by LWD, then the average bed stress $\tau_{G S}=\rho g \bar{h} \bar{s}_{w}$ and the LWD contribute a stress

$$
\tau_{\mathrm{LWD}}=\rho g \bar{h}\left(\bar{s}_{b}-\bar{s}_{w}\right)
$$

where $\bar{s}_{w}$ is the average water surface slope in the segments between trees. Because the water surface slope is about half the reach-averaged slope, the LWD must be responsible for about half the resistance to flow. Using $\bar{h}=0.36 \mathrm{~m}, \bar{s}_{b}=$ 0.0035 , and $\bar{s}_{w}=0.0018$, we obtain $\tau_{\text {LWD }} \approx 6.0 \mathrm{~Pa}$. This estimate is consistent with that found in section 4.2.

\subsection{Drag Inferred From Water Surface Steps}

The same result can be obtained directly from conventional energy balance arguments. Figure 3 shows that LWD are associated with abrupt steps in the water surface, indicating localized energy dissipation by LWD drag. The magnitude of this energy dissipation can be estimated straightforwardly. The energy per unit volume in a cross section of the flow is

$$
E_{m}=\rho g(z+h)+\frac{1}{2} \rho \alpha U^{2}=\rho g(z+h)+\frac{\rho \alpha q^{2}}{2 h^{2}},
$$

where $z$ is the bed elevation above some arbitrary datum, $q$ is the discharge per unit channel width, and $\alpha$ is a coefficient, typically between 1 and 1.4, that accounts for the fact that the square of the mean velocity is somewhat less than the mean of the squared velocities of the individual water parcels that comprise the flow [Richards, 1982]. If the water surface elevation drops by $\Delta h$, from $\bar{h}+\Delta h / 2$ to $\bar{h}-\Delta h / 2, E_{m}$ will be reduced by an amount

$\Delta E_{m} \approx-\rho g \Delta h+\frac{\rho \alpha q^{2} \Delta h}{h^{2} \bar{h}}=-\rho g \Delta h+\rho \alpha U^{2} \frac{\Delta h}{\bar{h}}$,

where the first and second terms represent the loss of potential energy and the gain of kinetic energy, respectively, and terms of order $(\Delta h / \bar{h})^{2}$ have been ignored. If $g h \gg \alpha U^{2}$ (which is equivalent to the condition that $F r^{2}$ in (7) is small), then the change in kinetic energy will be small compared to the change in potential energy. We can interpret the effect of LWD in terms of an average shear stress by summing the energy loss $-\Delta E_{m} \approx \rho g \Delta h$ over the cross section and averaging over the area of the bed, obtaining directly

$$
\tau_{\mathrm{LWD}} \approx \rho g \bar{h} \frac{\Delta h}{L},
$$

where $L$ is the spacing between LWD and its associated water surface steps. The ratio $\Delta h / L$ is simply the difference between the average bed slope $\bar{s}_{b}$ and the average water slope between trees $\bar{s}_{w}$, so (8) and (11) are equivalent. Of the total $31-\mathrm{cm}$ drop in the water surface elevation through the 90 -m surveyed reach, $16 \mathrm{~cm}$ occur in steps associated with LWD, implying that drag from LWD accounts for approximately half of the total energy dissipation, consistent with the analyses presented in sections 4.2 and 4.3 .

\subsection{Interaction Between LWD and the Bed}

Because the spring-fed streams apparently have no floods and a very limited supply of both bed and suspended materials, we expect the bed to be in near equilibrium with the existing flow. Direct observations of the streambed have never revealed any motion of the bed, though Whiting and Stamm [1995] observed bed transport in similar spring-fed streams. We now focus on a $200-\mathrm{m}$ stretch of the Cultus River, extending from the source of the springs to just above the entrance of a small runoff-dominated channel that can occasionally produce small springtime spikes in the Cultus River hydrograph [Manga, 1997]. The slope, width, depth, LWD density, and channel morphology are similar to that shown in Figure 3. In this segment of the river, macrophytes, which can have a large effect on flow and stress partioning, are generally absent. Farther downstream, macrophytes can cover more than $50 \%$ of the bed.

In order to determine the relationship between boundary shear stresses and the size of materials in the bed we measured shear stresses and the size distribution of particles in the bed. The local boundary shear stress $\tau_{0 l}$ is based on the measured mean velocity $U$ (see section 3 ) and is determined by

$$
\tau_{0 l}=\rho u_{*}^{2}
$$

with the shear velocity $u_{*}$ determined from [Wilcock et al., 1996]

$$
\frac{U}{u_{*}}=\frac{1}{\kappa} \ln \left(h / 0.258 d_{90}\right),
$$



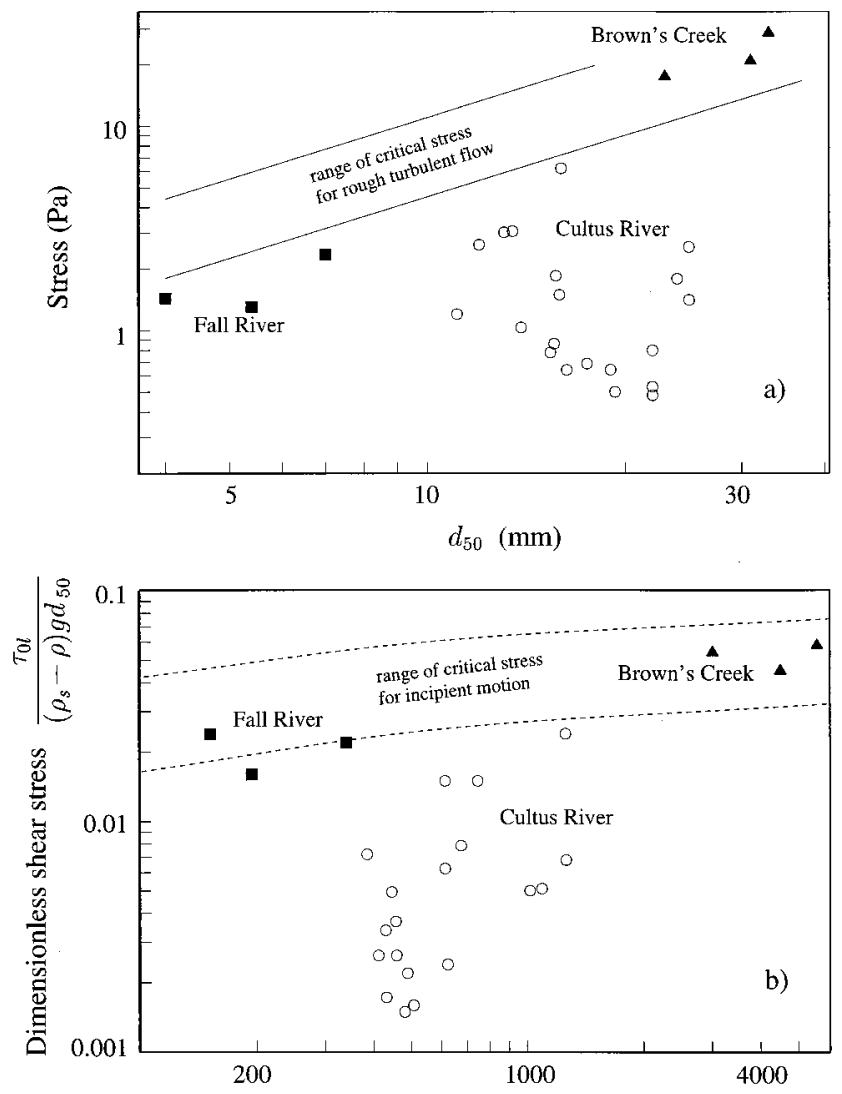

Reynolds number $\rho u_{*} d_{50} / \mu$

Figure 5. (a) Relationship between the local bed shear stress $\tau_{0 l}$ and the median size of particles in the bed $\left(d_{50}\right)$ in three spring-fed rivers: Fall River (squares), Brown's Creek (triangles), and Cultus River (circles). The Fall River and Brown's Creek data are from LWD-free reaches. (b) Same data as shown in Figure 5a, but plotted in dimensionless form. The dashed curves indicate the range of stresses required for incipient motion (range from Buffington and Montgomery [1997]).

where $\kappa=0.4$ is von Karman's constant and $d_{90}$ is the grain size for which $90 \%$ of the bed is finer. We attempted to sample the bed in bed form-free regions near the middle of the channel and as far away as possible from obstructions that might affect the vertical velocity profile.

In Figure 5a we show the relationship between bed size characterized by the median particle size $d_{50}$ and the measured local bed stress. In Figure $5 \mathrm{~b}$ we show the same data in dimensionless form: dimensionless local bed shear stress $\tau_{0 l} /$ $\left(\rho_{s}-\rho\right) g d_{50}$ as a function of the Reynolds number $\rho u_{*} d_{50} / \mu$. We assume that the density of the bed materials $\rho_{s}$ is $2650 \mathrm{~kg} / \mathrm{m}^{3}$. We also show data from reaches in two other spring-fed streams, Brown's Creek and the Fall River, that are unaffected by the presence of large woody debris in the channel. For comparison, in Figures 5a and 5b we also show estimates of the critical shear stress required for incipient motion of $d_{50}$. The upper and lower bounds in Figure $5 \mathrm{~b}$ are based on the compilation of measurements by Buffington and Montgomery [1997]; in Figure 5a we show these upper and lower bounds for the hydraulically rough limit.

In general, Figure 5 shows that shear stresses in the region between LWD, where the water surface slope is usually re- duced (Figure 3), are well below the critical values necessary to mobilize the bed even though flow is near bank-full. We can offer a qualitative explanation for these observations based on the importance of LWD in providing resistance. Assuming that there is no lag material from a previous geomorphic regime, in these nearly constant discharge streams we expect the size of the bed material to be determined by the largest stresses that the bed experiences, in this case, when LWD are absent. In the Fall River and Brown's Creek, measured stresses are near the critical value for the existing bed size, as we might expect in streams with nearly constant discharge and no LWD. In the absence of LWD, $\tau_{G S}$ is approximately $10 \mathrm{~Pa}$ (see Figure 4). We thus expect $d_{50}$ to be between $\sim 1$ and $3 \mathrm{~cm}$, consistent with the measured size of bed materials (Figure 5a).

Typical measured values of $\tau_{0 l}$ between LWD are lower than the value for $\tau_{G S}$ of $\sim 6 \mathrm{~Pa}$ that we might expect on the basis of Figure 4. This is because our sample sites were specifically chosen in regions where the local stress would be low, whereas $\tau_{G S}$ in Figure 4 is its average value over the entire bed.

\section{Concluding Remarks}

It has been well established that "hydraulically, debris acts as large roughness elements that provide a varied flow environment, reduce average velocity, and locally elevate the water surface profile" [Gippel, 1995, p. 388]. In the stream considered here, even though LWD cover less than $\sim 2 \%$ of the surface area of the stream, the LWD provide about half the total roughness or flow resistance. The streambed thus contains smaller grain sizes than we might expect on the basis of the total shear stress, consistent with inferences and results from other studies [e.g., Buffington and Montgomery, 1999].

Our focus here has been to relate theoretical results and field measurements. The particular stream we considered has many properties that simplify the interpretation of measurements. Specifically, the channel has a large width to depth ratio, a rectangular cross section, a nearly constant discharge, and a stable bed. The latter property greatly simplifies the analysis because we can, to a first approximation, neglect the effect of LWD on channel morphology and the resulting contribution of LWD-created bed forms to channel roughness. The LWD in these spring-fed channels resemble cylinders in a rectangular flume, and it is perhaps not surprising that our inferred drag coefficients are similar to those of cylinders in steady, uniform flow. The agreement between theory and fieldbased data suggests that the approach to quantifying the effect of LWD by calculating the various terms in a stresspartitioning equation (e.g., equation (2)) provides a convenient mathematical framework for initial assessment of the impacts of managed and natural changes in the debris loading of channels.

Acknowledgments. This work was supported by NSF grant EAR9701768. Bed and streamflow measurements were made with the help of S. Storch; the surveying was done with J. Stimac; the drag measurements on the floating log were made with E. Shuford. The authors thank J. Buffington, T. Lisle, and A. Robert for comments and suggestions.

\section{References}

Assani, A. A., and F. Petit, Log-jam effects and bed-load mobility from experiments conducted in a small gravel-bed forest ditch, Catena, 25, 117-126, 1995. 
Batchelor, G. K., An Introduction to Fluid Dynamics, Cambridge Univ. Press, New York, 1967.

Beechie, T. J., and T. H. Sibley, Relationships between channel characteristics, woody debris, and fish habitat in northwestern Washington streams, Trans. Am. Fish. Soc., 126, 217-229, 1997.

Bilby, R. E., Removal of woody debris may affect stream channel stability, J. For., 82, 609-613, 1984.

Buffington, J. M., and D. R. Montgomery, A systematic analysis of eight decades of incipient motion studies, with special reference to gravel-bedded rivers, Water Resour. Res., 33, 1993-2029, 1997.

Buffington, J. M., and D. R. Montgomery, Effects of hydraulic roughness on surface textures of gravel-bed rivers, Water Resour. Res., 35 , 3507-3521, 1999.

Church, M. A., D. G. McLean, and J. F. Wolcott, River bed gravels: Sampling and analysis, in Sediment Transport in Gravel-Bed Rivers, edited by C. R. Thorne, J. C. Bathurst, and R. D. Hey, pp. 43-88, John Wiley, New York, 1987.

Clifford, N. J., K. S. Richards, and A. Robert, The influence of microform bed roughness elements on flow and sediment transport in gravel bed rivers: Comment on a paper by Marwan A. Hassan and Ian Reid, Earth Surf. Processes Landforms, 17, 529-534, 1992.

Dudley, S. J., J. C. Fischenich, and S. R. Abt, Effect of woody debris entrapment on flow resistance, J. Am. Water Resour. Assoc., 34 1189-1197, 1998.

Einstein, H. A., and R. B. Banks, Fluid resistance of composite roughness, Eos Trans. AGU, 31, 603-610, 1950.

Gippel, C. J., Environmental hydraulics of large woody debris in streams and rivers, J. Environ. Eng., 121, 388-395, 1995.

Gippel, C. J., I. C. O'Neill, and B. L. Finlayson, The hydraulic basis of snag management, 115 pp., Cent. for Environ. Hydrol., Dept. of Civ. and Agric. Eng., Univ. of Melbourne, Melbourne, Victoria, Australia, 1992.

Gippel, C. J., I. C. O’Neill, B. L. Finlayson, and I. Schnatz, Hydraulic guidelines for the reintroduction and management of large woody debris in degraded lowland rivers, in Proceedings of the Conference on Habitat Hydraulics, pp. 225-239, Int. Assoc. for Hydraul. Res. Delft, Netherlands, 1994.

Gippel, C. J., I. C. O’Neill, B. L. Finlayson, and I. Schnatz, Hydraulic guidelines for the reintroduction and management of large woody debris in lowland rivers, Reg. Rivers Res. Manage., 12, 223-236, 1996.

Hey, R. D., Bar form resistance in gravel-bed rivers, J. Hydraul. Eng., 114, 1498-1508, 1988.

Li, R.-M., and H. W. Shen, Effect of tall vegetations on flow and sediment, J. Hydraul. Div. Am. Soc. Civ. Eng., 99, 793-814, 1973.

Lisle, T. E., Effects of coarse woody debris and its removal on a channel affected by the 1980 eruption of Mount St. Helens, Washington, Water Resour. Res., 31, 1797-1808, 1995.

Manga, M., A model for discharge in spring-dominated streams, and implications for the transmissivity and recharge of quaternary volcanics in the Oregon Cascades, Water Resour. Res., 33, 1813-1822, 1997.

Manga, M., On the timescales characterizing groundwater discharge at springs, J. Hydrol., 219, 56-69, 1999.

Montgomery, D. R., River management: What's best on the banks? Nature, 388, 328-329, 1997.

Nakamura, F., and F. J. Swanson, Effects of coarse woody debris on morphology and sediment storage of a mountain stream system in western Oregon, Earth Surf. Processes Landforms, 17, 43-61, 1993.

Nelson, J. M., S. R. McLean, and S. R. Wolfe, Mean flows and turbulence fields over two-dimensional bedforms, Water Resour. Res., 29, 3935-3953, 1993.

Nepf, H. M., Drag, turbulence, and diffusion in flow through emergent vegetation, Water Resour. Res., 35, 479-489, 1999.

Nowell, A. R. M., and M. Church, Turbulent flow in a depth limited boundary layer, J. Geophys. Res., 84, 4816-4824, 1979.

Piégay, H., and A. M. Gurnell, Large woody debris and river geomorphological pattern: Examples from SE France and S. England, Geomorphology, 19, 99-116, 1997.

Piégay, H., A. Thévenet, and A. Citterio, Input, storage and distribution of large woody debris along a mountain river continuum, the Drôme River, France, Catena, 35, 19-39, 1999.

Prestegaard, K. L., Bar resistance in gravel bed streams at bankfull stage, Water Resour. Res., 19, 473-476, 1983.

Ramamurthy, A. S., and C. P. Ng, Effect of blockage on steady force coefficients, J. Eng. Mech. Div. Am. Soc. Civ. Eng., 99, 755-772, 1973.

Ranga Raju, K. G., O. P. S. Rana, G. L. Asawa, and A. S. N. Pillai, Rational assessment of blockage effect in channel flow past smooth circular cylinders, J. Hydraul. Res., 21, 289-302, 1983.

Richards, K., Rivers: Form and Process in Alluvial Channels, 382 pp., Methuen, New York, 1982.

Robert, A., Characteristics of velocity profiles along riffle-pool sequences and estimates of bed shear stresses, Geomorphology, 19, 89-98, 1997.

Robison, E. G., and R. L. Beschta, Coarse woody debris and channel morphology interactions for undisturbed streams in southeast Alaska, USA, Earth Surf. Processes Landforms, 15, 149-156, 1990.

Scott, W. E., Quaternary glaciation and volcanism, Metolius River area, Oregon, Geol. Soc. Am. Bull., 88, 113-124, 1977.

Shields, F. D., and C. J. Gippel, Prediction of effects of woody debris removal on flow resistance, J. Hydraul. Eng., 121, 341-354, 1995.

Smith, R. D., R. C. Sidle, P. E. Porter, and J. R. Noel, Effects of experimental removal of woody debris on the channel morphology of a forest, gravel-bed stream, J. Hydrol., 152, 153-178, 1993.

Trimble, S. W., Stream channel erosion and change resulting from riparian forests, Geology, 25, 467-469, 1997.

Whiting, P. J., and J. Stamm, The hydrology and form of springdominated channels, Geomorphology, 12, 233-240, 1995.

Wilcock, P. R., A. F. Barta, C. C. Shea, G. M. Kondolf, W. V. Graham Matthew, and J. Pitlick, Observations of flow and sediment entrainment on a large gravel-bed river, Water Resour. Res., 32, 2897-2909, 1996.

Wohl, E. E., D. J. Anthony, S. W. Madsen, and D. M. Thompson, A comparison of surface sampling methods for coarse fluvial sediments, Water Resour. Res., 32, 3219-3226, 1996.

J. W. Kirchner, Department of Geology and Geophysics, University of California, Berkeley, CA 94720.

M. Manga, Department of Geological Sciences, University of Oregon, Eugene, OR 94703. (manga@newberry.uoregon.edu)

(Received December 27, 1999; revised May 11, 2000; accepted May 15, 2000.) 
